Optimal Monetary Policy with a Convex Phillips Curve

\author{
Demosthenes N. Tambakis
}

December 2008

CWPE 0859 


\title{
Optimal Monetary Policy with a Convex Phillips Curve
}

\author{
Demosthenes N. Tambakis* \\ Faculty of Economics \\ University of Cambridge
}

December 15, 2008

\begin{abstract}
This paper shows that convexity of the short-run Phillips curve is a source of positive inflation bias even when policymakers target the natural unemployment rate, that is when they operate with prudent discretion, and their loss function is symmetric. Optimal monetary policy also induces positive co-movement between average inflation, average unemployment and inflation variability - suggesting a new motive for inflation stabilization policy - and positively skewed unemployment distributions. The reduced form model is applied to the post-disinflation period (1986-2006) in developed countries and its properties are illustrated numerically for the United States.

Keywords: Monetary policy, inflation bias, inflation variability, prudent discretion
\end{abstract}

JEL classification codes: E24, E31, E52, E58

${ }^{*}$ I am grateful to Jon Faust and an anonymous referee for their suggestions. I would also like to thank Alan Blinder, Alex Cukierman, Andy Filardo, Athanasios Orphanides, and especially Doug Laxton for valuable comments on earlier versions of this paper. The usual disclaimer applies. E-mail address for correspondence: dnt22@cam.ac.uk. 


\section{Introduction}

A voluminous body of research has investigated the inflation bias result that average inflation exceeds the policymaker's inflation target. ${ }^{1}$ There are three possible reasons for excess inflation: $(a)$ the policymaker has a short-term incentive to lower unemployment below the natural rate, as in the Barro and Gordon (1983) framework; (b) monetary policy preferences are nonquadratic (asymmetric) such that, typically, unemployment deviations above target are weighted more than those below target; and $(c)$ the short-run inflationunemployment tradeoff is driven by a nonlinear (convex) Phillips curve.

The key premise of this paper is that, in addition to inflation bias, hypothesis $(c)$ is consistent with the positive relationship between average inflation, average unemployment and inflation variability, and can also generate asymmetric (positively skewed) unemployment distributions. In order to examine the role of the Phillips curve, we study discretionary monetary policy under hypothesis $(c)$ in a one-period model with complete information and symmetric policy preferences. The departure from certainty equivalence driving the model's equilibrium properties is then only due to the convex (nonlinear) inflation-unemployment tradeoff.

We are motivated by two stylized empirical observations. First, the widespread adoption of inflation targeting in developed countries over the past two decades has meant that, in the absence of institutional precommitment, policymakers may behave with prudent discretion, whereby the central bank knows the natural rate in each period and never wants unemployment to differ from it. The presence of an expansionary motive $\left(U^{*}<U^{N}\right.$, or $\left.k<1\right)$ has been challenged by Blinder (2000), McCallum (1997) and Gerlach (2003), among others, on the grounds that monetary policymakers do not systematically attempt to raise output above potential because they know that doing so is inflationary. Cukierman and Gerlach (2003) suggest that the unemployment target may have been time-varying: less than the natural rate in the 1970s, but rising along with the drive towards central bank independence in industrialized countries, such that prudent discretion $\left(U^{*}=U^{N}\right.$, or $\left.k=1\right)$ became feasible since the mid-1980s. ${ }^{2}$

Further, the level and variance of inflation in developed economies are positively correlated, over time and in cross-section; for recent surveys see

\footnotetext{
${ }^{1}$ Walsh (2003) reviews the sources of the time inconsistency problem in monetary policy.

${ }^{2}$ Svensson (1997) also argues that inflation targeting cannot be credibly implemented unless $k=1$.
} 
Kiley $(2000,2007)$. To the extent that this correlation persists in the recent post-disinflation period where setting $k=1$ is reasonable, an important consequence is that a prudent central bank should aim for stable inflation, as that is also lower on average. Inflation stabilization policy then has a first-order effect on social welfare.

Cukierman (2000) was the first to derive inflation bias by highlighting the asymmetry between hypotheses $(a)$ and $(b)$, that is when the unemployment target is the natural rate, and the loss is zero for negative unemployment deviations from target but increases quadratically for positive deviations. Subsequently, students of monetary policy have been exploring the nonlinear reaction functions arising from asymmetric policy preferences, and empirical support has been found for the U.S., G7 and OECD countries by RugeMurcia (2003a, 2004). ${ }^{3}$ Analytically, a shortcoming of these models is that, in order to show that inflation bias is positive when $k=1$, they require normally distributed inflation shocks (Gerlach (2003), Nobay and Peel (2003)), or uncertainty about economic conditions (Cukierman (2000), Cukierman and Gerlach (2003)), in addition to asymmetric policy preferences.

Against this background, the contributions of this paper are threefold. First, we identify the component of equilibrium inflation bias under convexity that was obtained generally by Dolado et al. (2005). As this component arises under prudent discretion $(k=1)$, it suggests an additional source of time inconsistency, one stemming from the interaction of the convex Phillips curve and the shock distribution. Excess average inflation arises because average unemployment in a stochastic convex economy exceeds the natural rate; see Laxton et al. (1999). ${ }^{4}$ Intuitively, higher unemployment reduces inflation less than lower unemployment increases it, so the first-order condition requires average inflation to also exceed its target. As the associated bias is unambiguously positive, it may have normative implications for the design of monetary institutions such as inflation targets.

Second, unlike the linear-symmetric model, we show that the convexsymmetric reduced form with prudent discretion yields a positive relationship between average inflation and inflation variability, and between average inflation and average unemployment. The first property suggests that a prudent

\footnotetext{
${ }^{3}$ In that literature, the central banker's "prudence motive" refers to the nonlinear reaction function due to asymmetric preferences; for example, see Ruge-Murcia (2002) and van der Ploeg (2004).

${ }^{4}$ Dolado et al. (2005) also derive a negative output bias, or a positive unemployment bias if the latter is used in the Phillips curve.
} 
central bank should aim for stable inflation even in a one-shot game with no asymmetric information, as inflation stabilization leads to lower average inflation. ${ }^{5}$ The second property is important to the extent that developed countries' inflation and unemployment rates co-move positively even when $k=1$, which cannot be accounted for by the linear model. Further, regarding the unemployment rate, the convex-symmetric model can shed light on the observation that unemployment distributions tend to be positively skewed. We show that skewed unemployment outcomes are a straightforward equilibrium property of discretionary monetary policy under convexity, and provide simulation evidence to that effect for the U.S.

Third, alongside the analytical focus on prudent discretion, the paper's empirical application is to the post-disinflation ("Great Moderation") period from 1986:1 to 2006:4. The advantage of this time period is that macroeconomic stability has arguably been achieved in most developed countries; see OECD (2002). Effectively, investigating the inflation-unemployment nexus over this period amounts to identifying sources of inflation bias independent of time-inconsistency issues and/or large adverse supply shocks, such as those of the 1970s.

The convex Phillips curve functional form in this paper follows Debelle and Laxton (1997) and Laxton, Rose and Tambakis (1999). ${ }^{6}$ At the aggregate level, convexity can be traced to the traditional Keynesian assumption that nominal wages are flexible upwards but rigid downwards, so that inflation is a decreasing and convex function of the unemployment rate equivalently, an increasing function of the output gap; see Layard et al. (1991) and Nickell (1997). At the microeconomic level, general equilibrium foundations are related to the principal-agent model of Shapiro and Stiglitz (1984).

Our reduced form framework is also related to research on the importance of time-inconsistency in monetary policy. In an influential paper, Ireland (1999) showed that, while the Barro-Gordon model combined with hypothesis (a) is capable of explaining the long-term dynamics of U.S. inflation and unemployment, it cannot account for their short-run behavior. Along these lines, Ruge-Murcia (2003b) finds that a more general version of Cukierman's asymmetric preferences combined with $k=1$ is better able to explain the U.S. data than Barro-Gordon. Albanesi et al. (2003) also show that time-

\footnotetext{
${ }^{5}$ The stabilization motive relates to the literature on nonlinear monetary policy rules; see Orphanides et al. (2006).

${ }^{6}$ Earlier work on nonlinear Phillips curves includes Clark et al. (1996), Dolado et al. (2004, 2005), Isard et al. (2003), Nobay and Peel (2000), and Tambakis (1999, 2002).
} 
inconsistency is not important for a wide range of parameter values in a general equilibrium model. Thus, prudent discretion offers a good operating environment for monetary policy during the "Great Moderation" period.

In the remainder of the paper, section 2 reviews the stylized facts on inflation and unemployment in advanced economies; Section 3 reviews the linear model; Section 4 presents the convex Phillips curve and derives optimal monetary policy when $k=1$; Section 5 applies the linear and convex models to international data and illustrates the latter's properties numerically for the U.S.; and Section 6 concludes.

\section{Inflation and unemployment: stylized facts}

The quarterly U.S. inflation and unemployment data for the period 1955:12006:4 are shown below ${ }^{7}$

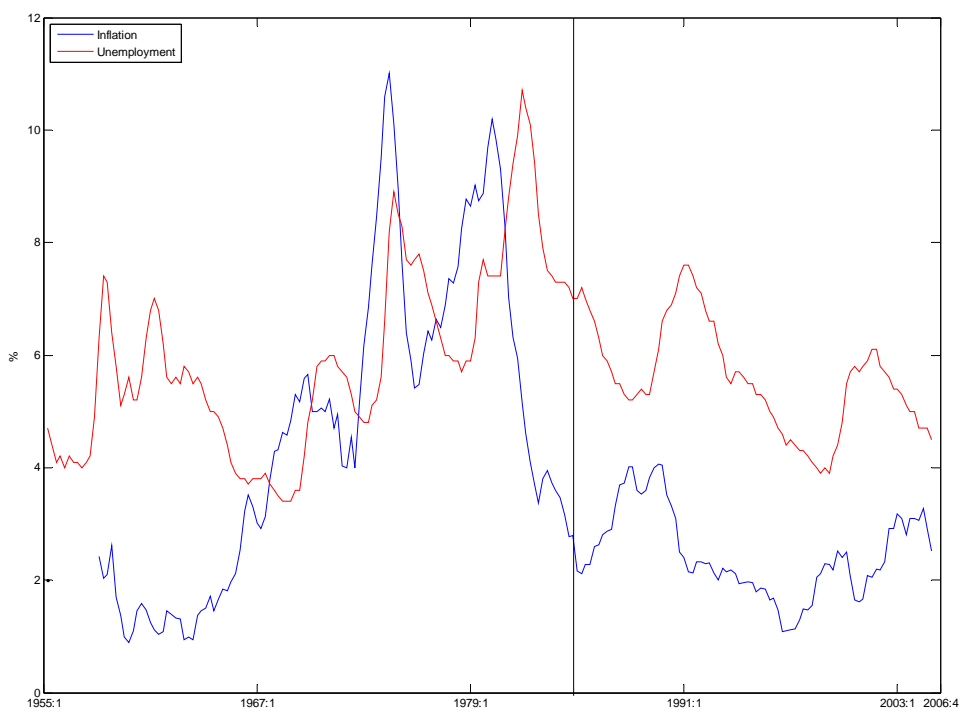

Figure 1: Quarterly inflation and unemployment rates, United States

\footnotetext{
${ }^{7}$ Inflation is the annualized quarterly percentage change of the GDP implicit price deflator. Source: IMF, IFS. Unemployment is the quarterly seasonally adjusted Standardized Unemployment Rates (SUR). Source: OECD, Main Economic Indicators.
} 
The two time series clearly co-move in the long run. ${ }^{8}$ Their correlation coefficient over the whole period is 0.34, declining to 0.19 from 1986:1-2006:4. This subperiod - highlighted by a vertical line in Figure 1-is arguably more relevant for prudent monetary policy, since the disinflation process from the high inflation of the 1970s has been completed. Note, also, that long-run correlations are more likely to be spurious: King and Watson (1997) find a significant break in the behavior of inflation and unemployment occuring around 1970 .

Turning to the link between inflation and its variability, we consider 20 OECD economies over the period 1986:1-2006:4 (84 observations/ country). ${ }^{9}$ A positive relationship is apparent from Figure 2 below

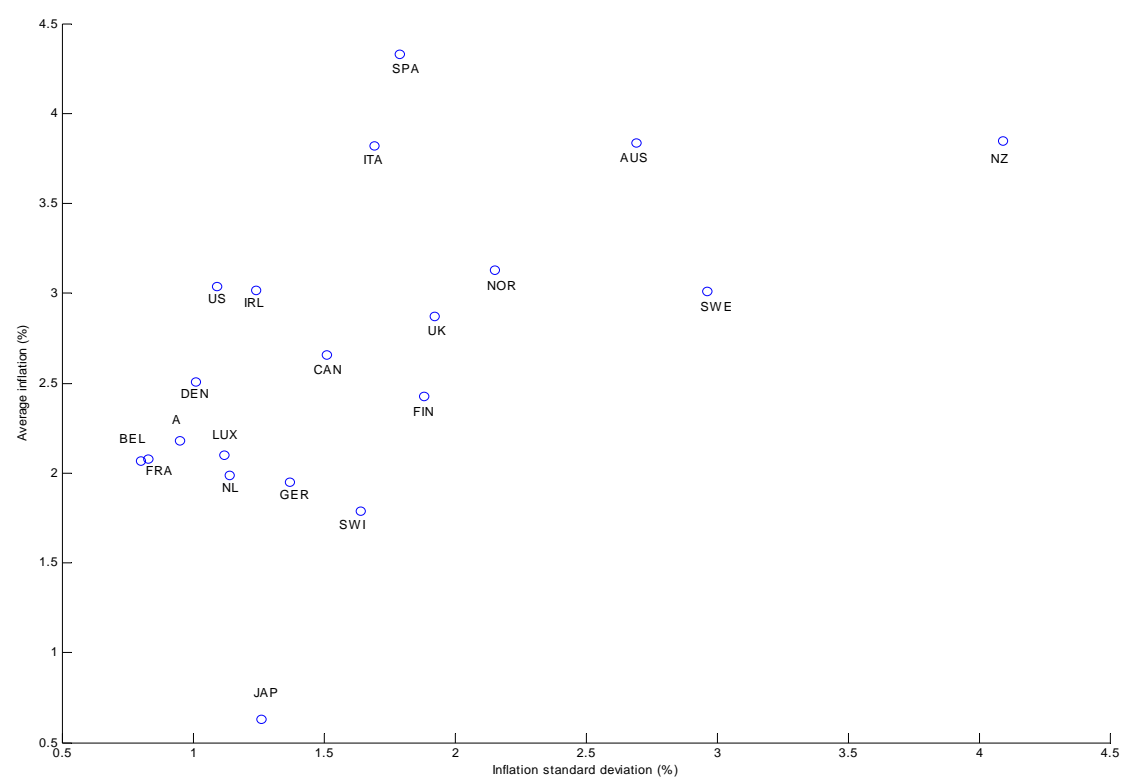

Figure 2: Average inflation and inflation variability in OECD countries

\footnotetext{
${ }^{8}$ Ireland (1999) found that U.S. inflation and unemployment time series are nonstationary and cointegrated using 1960:1-1997:2 data. We find a single cointegrating vector for 1986:1-2006:4; the test results are available upon request.

${ }^{9}$ We have excluded Greece and Portugal, the two moderate-to-high inflation countries in the cross-section, and Mexico and South Korea because they experienced financial crises and large currency fluctuations since the mid-1990s.
} 
Importantly, the correlation persists when discretionary monetary policy is prudent, in the sense of targeting the natural rate $(k=1)$. Table 1 highlights this by reporting five inflation-targeting countries' average inflation and inflation variability, from the date each implemented inflation targeting, denoted IT, as well as from 1986:1 through to 2006:4

Table 1. Inflation targeters' performance ${ }^{10}$

\begin{tabular}{|l|l|l|l|l|}
\hline & $I T-2006: 4$ & & $1986: 1-2006: 4$ & \\
\hline & $E \pi$ & $\sigma_{\pi}$ & $E \pi$ & $\sigma_{\pi}$ \\
\hline Australia, 1993:3 & 2.66 & 1.50 & 3.78 & 2.64 \\
\hline Canada, 1991:2 & 2.03 & 1.14 & 2.66 & 1.51 \\
\hline New Zealand, 1990:1 & 2.33 & 1.48 & 3.85 & 4.09 \\
\hline Sweden, 1993:2 & 1.39 & 1.26 & 3.01 & 2.96 \\
\hline United Kingdom, 1993:1 & 1.76 & 0.60 & 2.87 & 1.92 \\
\hline
\end{tabular}

Inflation and its variance co-move in all five inflation-targeting economies; the decline is more pronounced for Sweden and the UK because of the sharp devaluation of those countries' currencies following the ERM exchange rate crisis of September 1992. Hence, a rationale for active inflation stabilization policy is that it reduces average inflation also under prudent discretion, which characterizes the post-disinflation period. This stylized fact cannot be explained by the linear Barro-Gordon framework, where the first two moments of inflation are independent of each other. Put differently, the benefits of inflation stabilization policy appear to persist even after time-inconsistency problems have been overcome $(k=1)$ and an independent central bank has been established.

Developed country evidence also suggests that unemployment distributions are asymmetric and positively skewed. Table 2 below reports the skewness of unemployment rates in the inflation-targeting countries for the historical period starting in 1955:1, and for the post-disinflation period starting in 1986:1. The U.S. has also been included for comparison purposes.

\footnotetext{
${ }^{10} I T$ is the first quarter, reported next to each country's name, following the calendar month when it adopted inflation targeting. Source: Dotsey (2006).
} 
Table 2. Unemployment skewness ${ }^{11}$

\begin{tabular}{|l|l|l|}
\hline & $1955: 1-2006: 4$ & $1986: 1-2006: 4$ \\
\hline Australia & $-0.29^{\dagger}$ & 0.38 \\
\hline Canada & 0.23 & $0.47^{*}$ \\
\hline New Zealand & $\mathrm{n} / \mathrm{a}$ & $0.58^{*}$ \\
\hline Sweden & $0.77^{* *}$ & $-0.12^{\dagger}$ \\
\hline United Kingdom & $0.23^{* *}$ & $0.37^{*}$ \\
\hline United States & $0.75^{* *}$ & 0.26 \\
\hline
\end{tabular}

With the exception of Sweden, in the post-disinflation period the unemployment distribution has an asymmetric right tail, and the departure from normality, due to excess skewness and/or kurtosis, is significant for Canada, New Zealand and the U.K. Skalin and Teräsvirta (2002) find that long-run OECD unemployment data is highly nonlinear, but do not address skewness.

\section{The linear-symmetric benchmark}

In the reduced-form tradition of Kydland and Prescott (1977) and Barro and Gordon (1983) - henceforth referred to as the linear-symmetric modelmonetary policy minimizes expected quadratic losses

$$
E_{t-1} \mathcal{L}_{t}=E_{t-1}\left[\left(U_{t}-U^{*}\right)^{2}+b\left(\pi_{t}-\pi^{*}\right)^{2}\right]
$$

$\pi^{*} \geq 0$ and $U^{*}=k U^{N}(k \leq 1)$ are the one-period inflation and unemployment targets, $U^{N}$ is the natural rate of unemployment, and $b>0$ is the relative weight on inflation stabilization. The short-term surprise motive is zero only if $k=1$, that is when policymakers operate with prudent discretion. The economy is described by a linear short-run Phillips curve

$$
\pi_{t}=\pi_{t}^{e}+\beta\left(U^{N}-U_{t}\right)-\varepsilon_{t},
$$

where $1 / \beta$ is the constant sacrifice ratio and $\varepsilon_{t} \sim\left(0, \sigma_{\varepsilon}\right)$ is an independently and identically distributed (iid) aggregate supply shock. Alternatively, $\varepsilon_{t}$ can be interpreted as an inflation control error as in Ireland (1999): $\pi_{t}=\pi_{t}^{P}+\varepsilon_{t}$ where $\pi_{t}^{P}$ is planned inflation, and with rational expectations $\pi_{t}^{e}=\pi_{t}^{P}$.

\footnotetext{
${ }^{11}$ Superscripts $^{* *},{ }^{*}$ and ${ }^{\dagger}$ denote rejection of the null hypothesis of a normal distribution at 1, 5 and 10 percent, respectively, using the Jarque-Bera test on the raw unemployment rate data. Source: SUR unemployment, OECD Main Economic Indicators.
} 
The central bank then has no informational advantage over the private sector. It follows that unemployment fluctuates about the natural rate $U^{N}$, and its distribution is not skewed provided supply shocks are symmetric: $U_{t}=U^{N}-\frac{\varepsilon_{t}}{\beta}$. Minimizing (1) subject to (2) delivers positive inflation bias for all $k<1$

$$
E_{t-1} \pi_{t}=\pi^{*}+(1-k) \frac{U^{N}}{b \beta}>\pi^{*}
$$

Hence, in the linear-symmetric model, prudent discretion in monetary policy implies that the inflation rate meets its target on average; average inflation and unemployment are linearly related provided $k<1$; average inflation is independent of inflation variability regardless of the value of $k$; and monetary policy preferences $(b)$ cannot be identified when $k=1$, as inflation bias is then zero. We revisit the last point in Section 6 .

\section{The convex-symmetric alternative}

\subsection{The convex Phillips curve}

Alternatively, assume the structure of the economy is such that the central bank minimizes expected symmetric loss function (1) subject to the following convex short-run Phillips curve

$$
\pi_{t}=\pi_{t}^{e}+\gamma \frac{U^{N}-U_{t}}{U_{t}-\varphi}-\varepsilon_{t}, \quad 0 \leq \varphi<U^{N}
$$

In equation (4), due to Debelle and Laxton (1997) and Laxton et al. (1999), $\varepsilon_{t}$ is defined as in the linear case (2). $\varphi \geq 0$ is minimum unemployment, reflecting economy-wide short term capacity constraints, while $-\gamma<0$ is a horizontal asymptote defining the maximum unanticipated deflation if excess supply became unbounded. The Phillips curve becomes vertical as $\gamma \rightarrow \infty$.

The key equilbrium property of a convex short-run Phillips curve is that average unemployment exceeds the natural rate in a stochastic economy with symmetric shocks. Thus, a $\pm 1 \%$ inflation shock leads to $E_{t-1} U_{t}>U^{N}$. This departure from certainty equivalence described in Laxton et al. (1999)is independent of any loss function asymmetry and robust to the nonlinear functional form. ${ }^{12}$

\footnotetext{
${ }^{12}$ Dolado et al. (2004) adopt the same Phillips curve expressed in terms of the output gap. Nobay and Peel (2000) use a linex functional form due to Varian (1974) and Zellner (1986) that has also been used to capture asymmetric policy preferences.
} 
Convexity implies that the tradeoff between unanticipated inflation and unemployment improves continuously in the current unemployment rate, in contrast to the linear Phillips curve where the sacrifice ratio is constant. Differentiating (4), the slope of the Phillips curve is

$$
\frac{\partial U_{t}}{\partial \pi_{t}}=-\frac{\left(U_{t}-\varphi\right)^{2}}{\gamma\left(U^{N}-\varphi\right)}<0
$$

As unemployment declines below the natural rate, excess demand for labor and, hence, wage inflation grow disproportionately. Such structural statedependence was originally suggested in Phillips's (1958) pioneering work for the UK. ${ }^{13}$ It features in Taylor rules where the interest rate response depends on the current output gap (Clarida et al. (1999)), in nonlinear Taylor rules (Dolado et al. (2005), Orphanides et al. (2006)), and in models of downward nominal wage rigidity (Carlsson and Westermark (2008)).

Microfoundations for state-dependence can be found in the principalagent framework of Salop (1979) and Shapiro and Stiglitz (1984). In the latter model, the effective cost to workers for being caught shirking and becoming unemployed is increasing in their wage, and in the current unemployment rate. With imperfect monitoring of work effort, firms have to pay disproportionately higher wages when unemployment is low because workers' incentive to shirk is greater. Conversely, when unemployment is high, firms find they can lower wages without tempting workers to shirk. As the resulting wage premium increases smoothly in the state of the economy, a marginal unemployment decline becomes costlier in terms of unanticipated inflation than the corresponding marginal increase. Hence, moral hazard generates job-rationing which must be sufficiently large to induce labor to work rather than be caught shirking.

The convex curvature, $\gamma$, can thus be traced to labor market conditions. Shapiro and Stiglitz (1984) argue that such equilibrium unemploymentwhich increases in monitoring costs, workers' discount rates, and employers' costs from shirking - is significant and more likely to be of the blue-collar type.

The actual unemployment rate in period $t$ follows from equation (4)

$$
U_{t}=\frac{\gamma U^{N}+\varphi \varepsilon_{t}}{\gamma+\varepsilon_{t}}
$$

\footnotetext{
${ }^{13}$ Phillips argued that inflation's response to demand pressure is nonlinear and built this into estimation using the inverse unemployment rate.
} 
Equation (6) holds regardless of the value of $k$. Because $U^{N}>\varphi$, it requires that $\varepsilon_{t}>-\gamma$ for $U_{t}$ to not diverge. Note that this requirement does not affect the outcome, as inflation bias is clearly irrelevant in the divergent case. It suggests that Gaussian (infinite support) inflation control errors are not essential to the argument.

Further, unlike the linear-symmetric model, in Section 5.2 we show that simulating policy outcomes using symmetric inflation shocks in equation (6) induces asymmetric, right-skewed unemployment distributions. Such skewness appears consistent with the empirical evidence reviewed earlier.

\subsection{Optimal monetary policy when $k=1$}

The convex-symmetric model generates strictly positive expected inflation bias even if $k=1$. Minimizing expected loss function (1) subject to convex Phillips curve (4) yields the expected first-order optimality condition

$$
E_{t-1} \pi_{t}=\pi^{*}+\frac{1}{b} E_{t-1}\left[-\frac{\partial U_{t}}{\partial \pi_{t}}\left(U_{t}-k U^{N}\right)\right]
$$

Note that as average unemployment exceeds $k U^{N}$ for all $k \leq 1$, and the Phillips curve is negatively sloped, the second term in (7) is always positive. It follows that average inflation has to exceed $\pi^{*}$.

Specifically, setting $\pi^{*}=0$ without loss of generality, and substituting equations (4) and (5) into the first-order condition implies

$$
E_{t-1} \pi_{t}=\frac{1}{b \gamma\left(U^{N}-\varphi\right)} E_{t-1}\left[\left(U_{t}-\varphi\right)^{2}\left((1-k) U^{N}+\frac{\pi_{t}-\pi_{t}^{e}}{\gamma}\left(\varphi-U_{t}\right)\right)\right]
$$

Applying $\pi_{t}-\pi_{t}^{e}=\pi_{t}-E_{t-1} \pi_{t}=\varepsilon_{t}$ and (6) to this expression yields

$$
\begin{aligned}
E_{t-1} \pi_{t}= & (1-k) \frac{\gamma U^{N}\left(U^{N}-\varphi\right)}{b} E_{t-1} \frac{1}{\left(\gamma+\varepsilon_{t}\right)^{2}} \\
& -\frac{\gamma\left(U^{N}-\varphi\right)^{2}}{b} E_{t-1} \frac{\varepsilon_{t}}{\left(\gamma+\varepsilon_{t}\right)^{3}}
\end{aligned}
$$

The first term in (8) is zero when $k=1$. Therefore, if positive, the second term captures expected inflation bias in the absence of time-inconsistency. In their study of the effects of a quadratic Phillips curve on Taylor policy rules, Dolado et al. (2005) also break down inflation bias in two components, one in $1-k$ and one independent of time-inconsistency. 
The second term's contribution can be rewritten so that optimal prudent monetary policy delivers average inflation as follows

$$
\begin{aligned}
E_{t-1} \pi_{t} & =-\frac{\gamma\left(U^{N}-\varphi\right)^{2}}{b} E_{t-1} \frac{\varepsilon_{t}}{\left(\gamma+\varepsilon_{t}\right)^{3}} \\
& =-\frac{\left(U^{N}-\varphi\right)^{2}}{b \gamma} E_{t-1}\left[\frac{\varepsilon_{t}}{\gamma+\varepsilon_{t}}+\frac{\varepsilon_{t}^{3}}{\left(\gamma+\varepsilon_{t}\right)^{3}}-\frac{2 \varepsilon_{t}^{2}}{\left(\gamma+\varepsilon_{t}\right)^{2}}\right]
\end{aligned}
$$

As $\frac{\varepsilon_{t}}{\gamma+\varepsilon_{t}}$ is globally concave provided $\varepsilon_{t}>-\gamma$, the expectation of the first term in square brackets is negative from Jensen's inequality. The expectations of the second and third terms are written as $E_{t-1}\left[\frac{\varepsilon_{t}^{2}}{\left(\gamma+\varepsilon_{t}\right)^{2}}\left(\frac{\varepsilon_{t}}{\gamma+\varepsilon_{t}}-2\right)\right]$. This expression is negative for all $\varepsilon_{t}>-2 \gamma$, which is always true when $\varepsilon_{t}>-\gamma$. Premultiplying the square brackets by $-\frac{\left(U^{N}-\varphi\right)^{2}}{b \gamma}<0$, it follows that the RHS of (9) is strictly positive. Therefore, it constitutes a lower bound for expected inflation bias when $k=1$. Note that this lower bound would simply be shifted up by a constant if $\pi^{*}>0 .{ }^{14}$

The variances of actual inflation and inflation control errors $\left(\sigma_{\varepsilon}^{2}\right)$ are monotonically related when $k=1$; to see this, substitute $\pi_{t}=E_{t-1} \pi_{t}+\varepsilon_{t}$ in equation (9). Actual inflation then is

$$
\pi_{t}=-\frac{\gamma\left(U^{N}-\varphi\right)^{2}}{b} E_{t-1} \frac{\varepsilon_{t}}{\left(\gamma+\varepsilon_{t}\right)^{3}}+\varepsilon_{t}
$$

implying

$$
\operatorname{var} \pi_{t}=\frac{\gamma^{2}\left(U^{N}-\varphi\right)^{4}}{b^{2}} \operatorname{var} \widehat{\theta}+\sigma_{\varepsilon}^{2}
$$

where we define $\widehat{\theta} \equiv E_{t-1} \frac{\varepsilon_{t}}{\left(\gamma+\varepsilon_{t}\right)^{3}}=\frac{1}{T} \sum_{i=1}^{T} \frac{\varepsilon_{i}}{\left(\gamma+\varepsilon_{i}\right)^{3}}<0$. Recalling that inflation shocks are iid, the variance of $\widehat{\theta}$ is just

$$
\operatorname{var} \widehat{\theta}=\frac{1}{T^{2}} \sum_{i=1}^{T} \operatorname{var} \frac{\varepsilon_{i}}{\left(\gamma+\varepsilon_{i}\right)^{3}}
$$

\footnotetext{
${ }^{14}$ Nobay and Peel (2000) obtain equilibrium inflation bias using a linex Phillips curve functional form. However, the sign of the bias in their model in ambiguous, becoming positive only with sufficient preference uncertainty. Obtaining a closed-form solution also requires inflation shocks to be conditionally Gaussian.
} 
Equation (11) then becomes

$$
\operatorname{var} \pi_{t}=\frac{\gamma^{2}\left(U^{N}-\varphi\right)^{4}}{b^{2} T^{2}} \sum_{i=1}^{T}\left[\operatorname{var} \frac{\varepsilon_{i}}{\left(\gamma+\varepsilon_{i}\right)^{3}}\right]+\sigma_{\varepsilon}^{2}
$$

It follows that inflation variability converges asymptotically to $\sigma_{\varepsilon}^{2}$.

\section{Empirical analysis}

\subsection{Phillips curve estimates: developed countries}

The linear and convex Phillips curves are assessed for seven developed countries in the post-disinflation period 1986:1-2006:4, corresponding to $k=1$ in monetary policy. We consider the U.S., France, Germany, and four inflationtargeting countries from Section 2.

Our estimation procedure aims to facilitate a comparison of the two alternative specifications. Equations (2) and (4) are estimated using OLS. The underlying convex model is $\pi_{t}=\lambda \bar{\pi}_{t}^{e}+(1-\lambda) \pi_{t-1}+\gamma f\left(U_{t}, U^{N}\right)+\varepsilon_{t}^{\pi}$, where $f\left(U_{t}, U^{N}\right)=\frac{U^{N}-U_{t}}{U_{t}-\varphi}$, and $\varphi=2$ percent, following Laxton et al. (1999). The linear model is $\pi_{t}=\lambda \bar{\pi}_{t}^{e}+(1-\lambda) \pi_{t-1}+\beta\left(U^{N}-U_{t}\right)+\varepsilon_{t}^{\pi}$. Expected inflation for each country is specified as a twelve-quarter distributed lag of past inflation, $\bar{\pi}_{t}^{e}=\left(\sum_{i=1}^{12} \pi_{t-i}\right) / 12$, and intrinsic inflation persistence is represented by the first lag of $\pi_{t}$. The weights on the expected future and lagged inflation terms must sum to unity to ensure no long-run tradeoff between inflation and unemployment.

In the estimated models we impose $\lambda=1$ and fix the natural unemployment rate at its period average (84 quarterly observations, except New Zealand with 62). These restrictions are maintained against evidence of time-variation in the natural rate and a pure backward-looking component in inflation. However, given the small sample size, a full econometric investigation lies beyond the scope of this paper. ${ }^{15}$ Accordingly, we denote inflation shocks by $\varepsilon_{t}^{\pi}$ to draw attention to the fact that the errors are different from the theoretical model. The least-squares country estimates of the linear Phillips curve are reported in Table 3

\footnotetext{
${ }^{15}$ Gordon (1997), King and Watson (1997) and Laxton et al. (1999) estimate U.S. Phillips curves (linear and nonlinear) with a time-varying unobserved natural rate.
} 
Table 3. Estimated Linear Phillips Curves: 1986:1-2006: $4^{16}$

\begin{tabular}{|l|l|l|l|l|l|}
\hline$\pi_{t}=\lambda \bar{\pi}_{t}^{e}+\beta\left(U^{N}-U_{t}\right)+\varepsilon_{t}^{\pi}$ & $\beta$ & $\lambda$ & $\mathrm{LM}$ & $\sigma_{\varepsilon}$ & $U^{N}(\%)$ \\
\hline Australia & $0.42^{* *}$ & $0.68^{* *}$ & 1.37 & 2.39 & 7.4 \\
\hline France & $0.26^{\dagger}$ & $0.37^{* *}$ & $2.14^{*}$ & 1.48 & 9.9 \\
\hline Germany & 0.03 & $0.76^{* *}$ & 1.43 & 2.69 & 7.6 \\
\hline New Zealand & 0.25 & -0.34 & $1.81^{\dagger}$ & 3.69 & 6.4 \\
\hline Sweden & $0.62^{* *}$ & $0.38^{*}$ & 1.02 & 4.67 & 5.8 \\
\hline United Kingdom & 0.15 & $0.79^{* *}$ & 1.48 & 2.40 & 7.2 \\
\hline United States & $0.18^{\dagger}$ & $0.85^{* *}$ & 1.41 & 0.67 & 5.6 \\
\hline
\end{tabular}

The results indicate that the linear Phillips curve slope is small and not significant for European Union countries, except Sweden. It is significant for Australia and less so for the U.S. Note that the U.S. slope estimate, $\widehat{\beta}=0.18$ yields an unrealistically large sacrifice ratio. Also, with the exception of France and the U.S., the country regressions' estimated standard errors are large when compared to those in Laxton et al. (1999) and Gordon (1997) for the U.S., respectively $1.49 \%$ and $1.56 \%$.

The convex Phillips curve country estimates are reported in Table 4

Table 4. Estimated Convex Phillips Curves: 1986:1-2006:4 ${ }^{17}$

\begin{tabular}{|l|l|l|l|l|}
\hline$\pi_{t}=\lambda \bar{\pi}_{t}^{e}+\gamma\left(\frac{U^{N}-U_{t}}{U_{t}-\varphi}\right)+\varepsilon_{t}^{\pi}$ & $\gamma$ & $\lambda$ & $\mathrm{LM}$ & $\sigma_{\varepsilon}$ \\
\hline Australia & $1.39^{*}$ & $0.65^{* *}$ & 1.56 & 2.40 \\
\hline France & $2.72^{*}$ & $0.44^{* *}$ & $1.82^{\dagger}$ & 1.42 \\
\hline Germany & $0.86^{*}$ & $0.64^{* *}$ & $1.65^{\dagger}$ & 2.70 \\
\hline New Zealand & $0.65^{\dagger}$ & -0.44 & $1.91^{\dagger}$ & 3.68 \\
\hline Sweden & $0.07^{\dagger}$ & $0.78^{* *}$ & 1.24 & 4.96 \\
\hline United Kingdom & -0.31 & $0.59^{*}$ & 1.55 & 2.44 \\
\hline United States & 0.29 & $0.76^{* *}$ & 1.30 & 0.62 \\
\hline
\end{tabular}

\footnotetext{
${ }^{16}$ Superscripts ${ }^{* *},{ }^{*}$ and ${ }^{\dagger}$ denote rejection of the null hypothesis of zero coefficients at 1, 5 and 10 percent, respectively, under the $t$-distribution. LM is the Breusch-Godfrey $F$-statistic for the null of no residual autocorrelation up to 12 lags. $\sigma_{\varepsilon}$ is the standard error of the regression (quarterly, at annual rates). The error terms follow low-order MA processes - not reported to save space - to absorb residual autocorrelation.

${ }^{17}$ The natural rate estimates are the unemployment averages reported in Table 3.
} 
The least-squares estimates in Table 4 suggest that the convex curvature $(\gamma)$ is modestly large and significant for France, Germany and Australia, but not for Sweden, the U.K. and the U.S. The estimated values of $\lambda$ are less than one and mostly significant. ${ }^{18}$ For illustration purposes, Figure 3 compares the fitted linear (in red) and convex functions (in blue) for the U.S. and the Euro area, along with scatter plots of the unemployment rate and inflation differential, defined as $\pi_{t}-\bar{\pi}_{t}^{e}$. For the Euro area we have used $\varphi=5$ percent, reflecting its higher average unemployment rates.
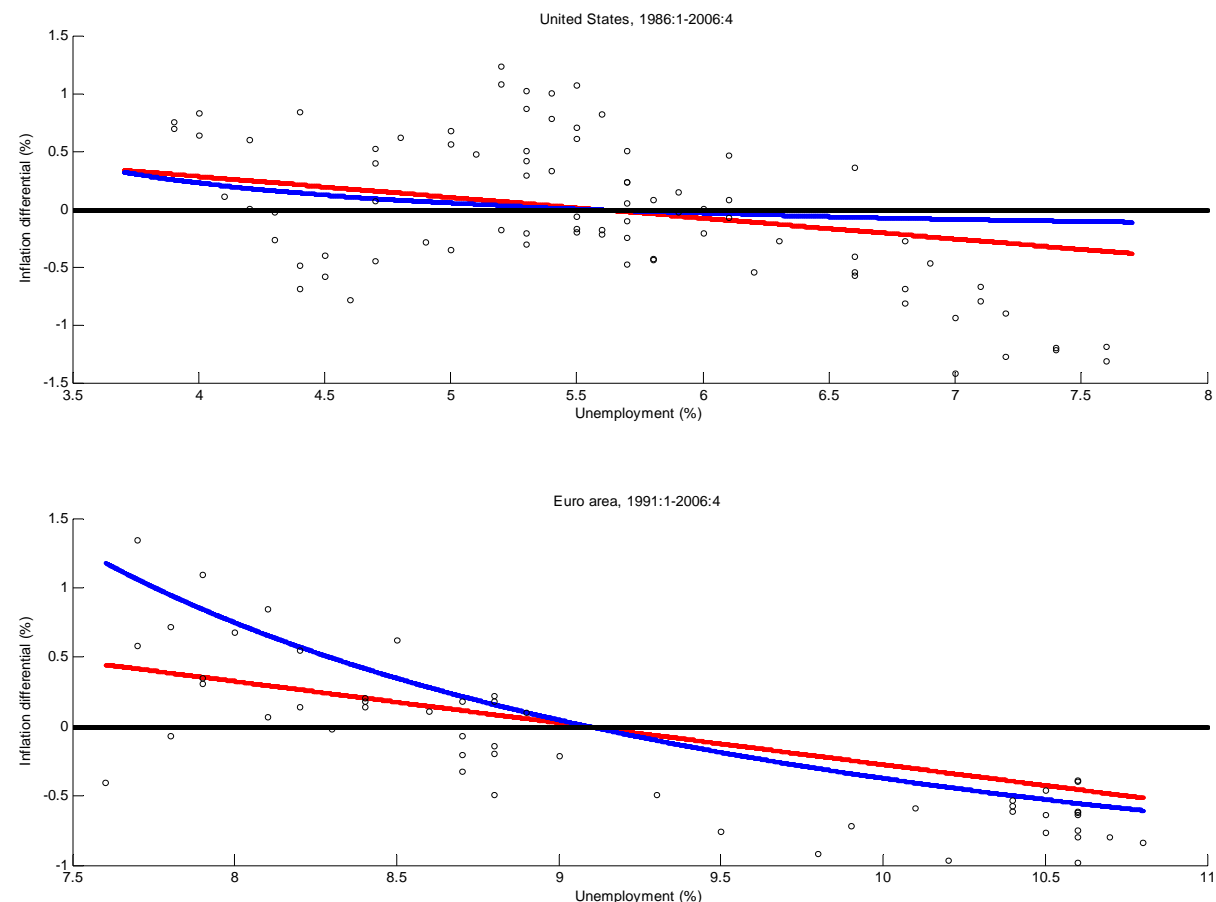

Figure 3: Linear and convex Phillips curves, United States and Euro area ${ }^{19}$

For the U.S., it can be observed that the convex model's fit is not substantially different from the linear benchmark. In contrast, for the Euro area the

\footnotetext{
${ }^{18}$ Allowing $\lambda<1$ in the estimation would cause collinearity, as $\pi_{t-1}$ is already included in $\bar{\pi}_{t}^{e}$. The smaller sample size for New Zealand may explain the wrong sign of $\lambda$.

${ }^{19}$ The U.S data is from 1986:1-2006:4. Inflation in the Euro-area is the annualized quarterly percentage change in the CPI, 1991:1-2006:4. Source: European Central Bank.
} 
convex Phillips curve fits the inflation differential-unemployment rate data better. This stylized observation was also reached by Dolado et al. (2005) using a quadratic Phillips curve. The Euro area's more outlying observations are likely due to higher nominal wage rigidity; see Nickell (1997).

Overall, the regression results should be treated with caution on account of the small sample size and the simple dynamic specification. After controlling for inflation persistence, the linear Phillips curve seems to fit the U.S. and Swedish data better than the convex alternative, while for France and Germany the reverse is the case. Neither model is appropriate for the U.K., but both seem to fit the Australian data. These findings are broadly consistent with Dolado et al. (2004, 2005), who report that the interest-rate behavior resulting from a convex Phillips curve fits the experience of 3 European countries and the euro area, but not the U.S. We tentatively conclude that the convex Phillips curve is relevant for the post-disinflation period in developed countries' monetary policy .

\subsection{Numerical simulations: United States}

We use numerical simulations to illustrate the convex-symmetric model's properties for the United States. From equation (10), expected inflation is a function of period- $t$ shocks and the model's parameters. Imposing $k=1$, the equilibrium relation between average inflation and inflation variability is assessed by evaluating inflation outcomes for a large number of shocks.

The simulations are based on the U.S. structural parameter estimates of Laxton et al. (1999). Assuming the unobservable time-varying $U_{t}^{N}$ process has a unit root, and employing the Kalman filter to estimate the natural rate from 1968:1-1997:1, these authors' ML estimates for convex Phillips curve (4) were: $\widehat{\gamma}=4.71, \widehat{U}^{N}=6.1$ percent, and $\widehat{\varphi}_{t}=\max \left(0, U_{t}^{N}-4\right)=2.1$ percent. Average unemployment over that period was 6.4 percent, yielding an estimated mean unemployment gap of 0.3 percent. The annual inflation target is set at $2 \%$, without loss of generality.

We let $\sigma_{\varepsilon}$ vary between 0.5 and 2 in steps of size 0.01 and simulate 100,000 one-period inflation outcomes at each step. Because inflation outcomes diverge as $\varepsilon_{t}$ approach $-\gamma$, we use a uniform probability density function symmetric around zero. The standard deviation of a symmetric uniform pdf with support $[-a, a]$ is $a / \sqrt{3}$. Thus, using Laxton et al.'s regression standard error estimate $\widehat{\sigma}_{\varepsilon}=1.49$ as the benchmark, inflation shocks are generated from a uniform with support $\left[-\sqrt{3} \widehat{\sigma}_{\varepsilon}, \sqrt{3} \widehat{\sigma}_{\varepsilon}\right]$, or $[-2.58,2.58]$, implying $\varepsilon_{t}>-\widehat{\gamma}$ is 
always satisfied. ${ }^{20}$

The resulting combinations of average inflation and inflation standard deviation $\left(\sigma_{\varepsilon}\right)$ are shown in the top panel of Figure 4
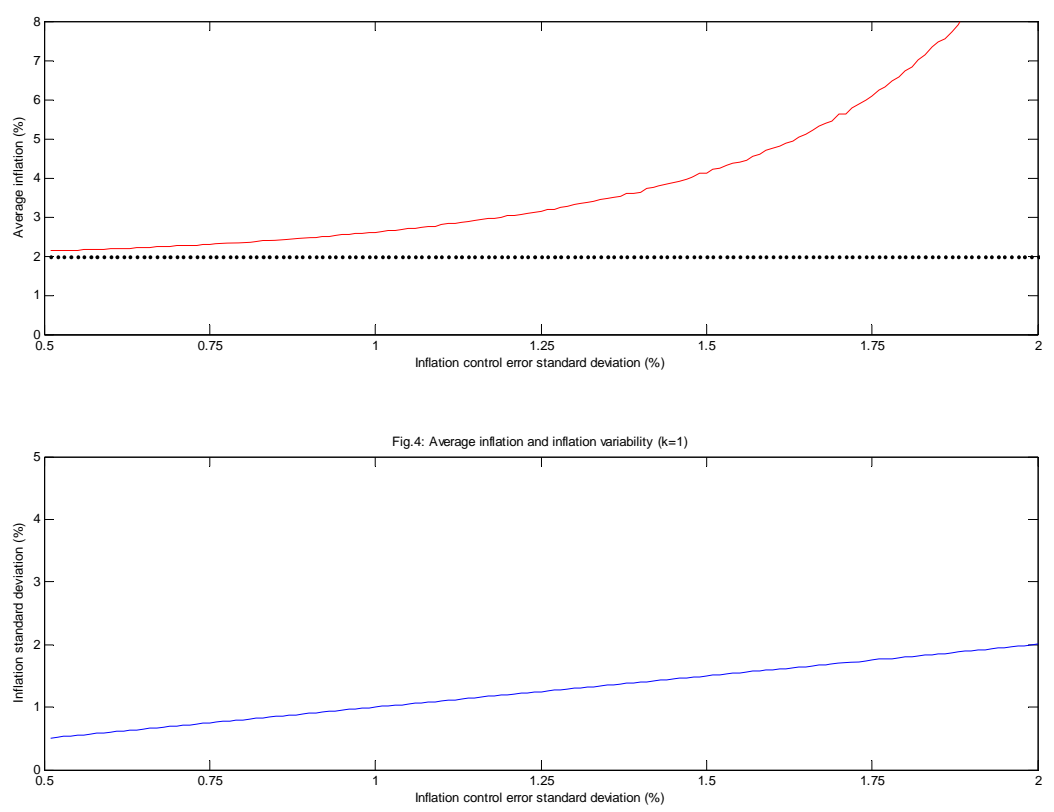

Figure 4: Simulated average U.S. inflation and inflation variability $(k=1)$

In contrast to the linear-symmetric model, average inflation increases with $\sigma_{\varepsilon}$ also if $k=1$. Moreover, the rate of increase is higher as inflation becomes more volatile for any given convex curvature. Average unemployment (not shown) also increases in $\sigma_{\varepsilon}$. Note that at $\sigma_{\varepsilon}=1.49 \%$ average inflation is above 4 percent, close to the historical average for the 1968:1-1997:1 period. The bottom panel of Figure 4 presents the standard deviation of simulated inflation $\left(\sigma_{\pi}\right)$ against that of inflation shocks $\left(\sigma_{\varepsilon}\right)$. This relationship is linear for large sample sizes, as shown in equation (12).

\footnotetext{
${ }^{20}$ The results are robust to normally distributed shocks. However, a normal pdf would have to be arbitrarily truncated to exclude extreme negative errors, i.e. big deflationary surprises.
} 
Simulation results for the equilibrium relationship between average inflation and unemployment rates when $k=1$ are shown below

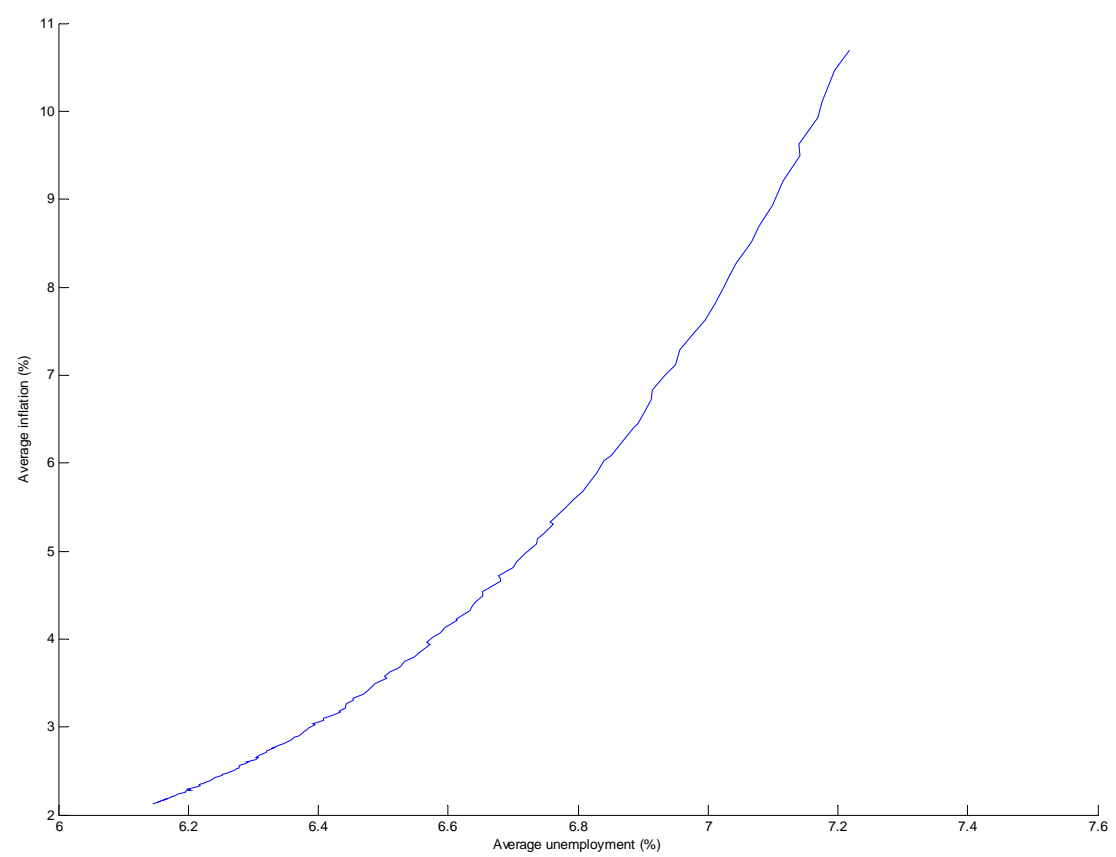

Figure 5: Simulated average U.S. inflation and unemployment $(k=1)$

Average inflation and unemployment co-move together. This has important implications for monetary policy: it indicates that inflation and unemployment are likely to be cointegrated also under prudent discretion. The convexity of the slope reflects the improving short-run tradeoff (lower sacrifice ratio) as unemployment declines.

In order to simulate U.S. unemployment outcomes, we have applied three different uniform distributions of inflation control errors to equation (6). The regression standard errors used to find the uniform pdf support for the simulations were: 0.62 (from the U.S. convex Phillips curve in Table 4), 1.49 (from the convex Phillips curve in Laxton et al. (1999)), and 1.56 (from the linear Phillips curve in Gordon (1997)). Positive skewness is apparent from the simulations reported in Table 5 
Table 5. U.S. unemployment skewness: simulation results ${ }^{21}$

\begin{tabular}{|l|l|l|l|l|}
\hline Inflation control errors & Mean & Median & Skewness & Kurtosis \\
\hline 1. uni $[ \pm 1.07], \sigma_{\varepsilon}=0.62$ & 6.2 & 6.1 & 0.33 & 1.93 \\
\hline 2. uni $[ \pm 2.58], \sigma_{\varepsilon}=1.49$ & 6.6 & 6.1 & 0.90 & 2.81 \\
\hline 3. uni $[ \pm 2.79], \sigma_{\varepsilon}=1.56$ & 6.7 & 6.1 & 0.94 & 2.91 \\
\hline
\end{tabular}

In all three cases, the Jarque-Bera test rejects the null of a normal unemployment distribution at 0.99 confidence. As expected, positive skewness is significantly smaller when the uniform shocks are calibrated to the standard error of inflation in the prudent discretion period (case 1) than to the larger standard errors from 1967 to 1997 (cases 2 and 3). Recall that this was also the case for the descriptive statistics reported in Table 2 for the U.S.; as argued by Laxton et al. (1999), it is harder to identify convexity in small sample sizes. Overall, the simulation results suggest that the convexsymmetric reduced form can readily account for asymmetric (right-skewed) unemployment distributions.

\section{Concluding remarks}

This paper showed that combining symmetric losses with a convex Phillips curve generates positive inflation bias in a reduced-form monetary policy model. This result - obtained by Dolado et al. (2005) and Ruge-Murcia (2003b) for asymmetric loss functions - holds also when the central bank targets the natural unemployment rate, i.e., when discretionary policy is prudent.

Identifying such a structural source of bias may have important normative implications for designing monetary institutions, e.g., inflation targets and performance contracts for central bankers. It suggests an additional source of excess average inflation stemming from the interaction of the convex Phillips curve and the shock distribution. Such inflation bias may also be relevant against the background of growing financial market instability since 2007 and the global credit crisis in 2008. To the extent that the monetary authority can affect financial stability above and beyond keeping inflation low and

\footnotetext{
${ }^{21}$ The structural parameter values are as in Figs. 3 and 4 . The sample mean, median (in percent), skewness and kurtosis were computed for 100,000 inflation control errors. The empirical histograms are available upon request.
} 
stable, it is not clear that inflation targeting alone will deliver the optimal amount of influence on financial stability as, with a convex Phillips curve, more variable inflation is also higher on average. At the same time, this equilibrium property has clear positive implications: it provides a distinct motive for inflation stabilization even if the policy maker can precommit and preferences are symmetric. It is also in line with proponents of enhancing central bank credibility, as lower average inflation yields a first-order welfare improvement; for example, Clarida et al. (1999).

Further, it was shown that average inflation increases in average unemployment, and unemployment outcomes are positively skewed. The first result is important as it helps to account for the persistently positive correlation between average inflation and unemployment since the mid-1980s, which is impossible in the linear-symmetric model; see Ireland (1999). The second result refers to actual unemployment, so it is empirically less controversial than if it involved the output gap and the uncertainty over potential output measures. Least-squares estimation and numerical methods indicated that the convex-symmetric model is broadly consistent with developed economies' experience during the "Great Moderation" period. A simple comparison also suggested that the convex model fits the Euro-area's data better than the linear one, unlike the United States. This stylized finding, confirming that of Dolado et al. (2005) using a quadratic Phillips curve in terms of the output gap, is also consistent with higher average unemployment in Europe.

More generally, notwithstanding the empirical difficulties of identifying convexity in the Phillips curve, a nonlinear policy reaction function may be easier to assess if the underlying departure from certainty equivalence is due to a structural parameter rather than an unobserved preference coefficient. In that respect, the convex alternative allows the symmetric inflation aversion coefficient $(b)$ to be identified also under prudent discretion and quadratic losses. Thus, to the extent that central banks' (and society's) relative weight on inflation stabilization may have changed significantly since the early 1980s in response to economic events, inferring time-varying monetary policy preferences from macroeconomic outcomes is a potential application of the convex-symmetric reduced form. 


\section{References}

[1] Albanesi, S., V. Chari and L. Christiano (2003): "How Severe is the Time-Inconsistency Problem in Monetary Policy?" Federal Reserve Bank of Minneapolis Quarterly Review, 27, 17-33.

[2] Barro, R. and D. Gordon (1983): "A Positive Theory of Monetary Policy in a Natural-Rate Model", Journal of Political Economy, 91, 589-610.

[3] Blinder, A. (2000): "Central Bank Credibility: Why do we Care? How do we Build it?" American Economic Review, 90, 1421-1431.

[4] Carlsson, M. and A. Westermark (2008): "Monetary Policy under Downward Nominal Wage Rigidity" Advances in Macroeconomics, B.E. Press, 8, Article 28.

[5] Clarida, R., J. Gali and M. Gertler (1999): "The Science of Monetary Policy: A New Keynesian Perspective", Journal of Economic Literature, 37, 1661-1707.

[6] Clark, P., D. Laxton and D. Rose (1996): "Asymmetry in the U.S. Output-Inflation Nexus: Issues and Evidence", IMF Staff Papers 43, Washington, D.C.

[7] Cukierman, A. (2000): "The Inflation Bias Result Revisited", Tel-Aviv University, mimeo.

[8] Cukierman, A. and S. Gerlach (2003): "The Inflation Bias Revisited: Theory and some International Evidence", Manchester School, 71, 541565.

[9] Debelle, G. and D. Laxton (1997): "Is the Phillips Curve really a Curve? Some Evidence for Canada, the United Kingdom and the United States", IMF Staff Papers 44, International Monetary Fund, Washington.

[10] Dolado, J., R. Pedrero and F. Ruge-Murcia (2004): "Nonlinear Monetary Policy Rules: Some New Evidence for the U.S.", Studies in Nonlinear Dynamics and Econometrics, 8(3), Article 2.

[11] Dolado, J., R. Pedrero and M. Naveira (2005): "Are Monetary-Policy Reaction Functions Asymmetric? The Role of Nonlinearity in the Phillips Curve", European Economic Review, 49, 485-503. 
[12] Dotsey, M. (2006): "A Review of Inflation Targeting in Developed Countries", Philadelphia Fed Business Review, 3, 10-20.

[13] Gerlach, S. (2003): "Recession Aversion, Output and the KydlandPrescott Barro-Gordon Model", Economics Letters, 81, 389-394.

[14] Gordon, R. (1997): "The Time-varying NAIRU and its Implications for Economic Policy", Journal of Economic Perspectives, 11, 11-32.

[15] Ireland, P. (1999): "Does the Time-Consistency Problem Explain the Behavior of Inflation in the United States?", Journal of Monetary Economics, 44, 279-291.

[16] Isard, P., D. Laxton and C. Eliasson (2001): "Inflation Targeting with NAIRU Uncertainty and Endogenous Policy Credibility", Journal of Economic Dynamics and Control, 25, 115-148.

[17] Kiley, M. (2000): "Price Stickiness and Business Cycle Persistence", Journal of Money, Credit and Banking, 32, 28-53.

[18] Kiley, M. (2007): "Is Moderate-to-high Inflation Inherently Unstable?", International Journal of Central Banking, 3, 173-201.

[19] King, R. and M. Watson (1997): "The Post-war U.S. Phillips Curve: A Revisionist Econometric History", Carnegie-Rochester Conference Series on Public Policy, 41, 157-219.

[20] Kydland, F. and E. Prescott (1977): "Rules rather than Discretion: The Inconsistency of Optimal Plans", Journal of Political Economy, 85, 473-492.

[21] Layard, R., S. Nickell, and R. Jackman (1991): Unemployment, Oxford: Oxford University Press.

[22] Laxton, D., D. Rose, and D. Tambakis (1999): "The U.S. Phillips Curve: The Case for Asymmetry", Journal of Economic Dynamics and Control, 23, 1459-1485.

[23] McCallum, B. (1997): "Critical Issues Concerning Central Bank Independence", Journal of Monetary Economics, 39, 99-112. 
[24] Nickell, S. (1997): "Unemployment and Labor Market Rigidities: Europe versus North America", Journal of Economic Perspectives, 11, 5574 .

[25] Nobay, R. and D. Peel (2000): "Optimal Monetary Policy with a Nonlinear Phillips Curve", Economics Letters, 67, 159-164.

[26] Nobay, R. and D. Peel (2003): "Optimal Discretionary Monetary Policy in a Model of Asymmetric Central Bank Preferences", Economic Journal, 113, 657-665.

[27] Organisation for Economic Cooperation and Development, OECD (2002): Economic Outlook 71.

[28] Orphanides, A., D. Small, V. Wieland and D. Wilcox (2006): "A Quantitative Exploration of the Opportunistic Approach to Disinflation", Journal of Monetary Economics, 53, 1877-1893.

[29] Phillips, A. (1958): "The Relation between Unemployment and the Rate of Change of Money Wage Rates in the United Kingdom 1861-1957", Economica, 25, 283-299.

[30] Ruge-Murcia, F. (2002): "A Prudent Central Banker", IMF Staff Papers, 49, 456-469.

[31] Ruge-Murcia, F. (2003a): "Inflation Targeting under Asymmetric Preferences", Journal of Money, Credit and Banking, 35, 763-785.

[32] Ruge-Murcia, F. (2003b): "Does the Barro-Gordon Model Explain the Behavior of U.S. Inflation? A Reexamination of the Empirical Evidence", Journal of Monetary Economics, 50, 1375-1390.

[33] Ruge-Murcia, F. (2004): "The Inflation Bias when the Central Banker targets the Natural Rate of Unemployment", European Economic Review, 48, 91-107.

[34] Salop, S. (1979): "A Model of the Natural Rate of Unemployment", American Economic Review, 69, 117-125.

[35] Shapiro, C. and J. Stiglitz (1984): "Equilibrium Unemployment as a Worker Discipline Device", American Economic Review, 72, 433-444. 
[36] Skalin, J. and T. Teräsvirta (2002): "Modeling Asymmetries and Moving Equilibria in Unemployment Rates", Macroeconomic Dynamics, 6, 202241.

[37] Svensson, L. (1997): “Optimal Inflation Targets, 'Conservative' Central Banks and Linear Inflation Contracts", American Economic Review, 87, 98-114.

[38] Tambakis, D. (1999): "Monetary Policy with a Nonlinear Phillips Curve and Asymmetric Loss", Studies in Nonlinear Dynamics and Econometrics, 3, 223-237.

[39] Tambakis, D. (2002): "Expected Social Welfare under a Convex Phillips Curve and Asymmetric Policy Preferences", Journal of Money, Credit and Banking, 34, 434-449.

[40] Van der Ploeg, F. (2004): "Prudent Monetary Policy: Applications of Cautious LQG Control and Prediction", CEPR working paper 4222, February.

[41] Varian, H. (1974): "A Bayesian Approach to Real Estate Assessment", in Feinberg, S. and A. Zellner, eds., Studies in Bayesian Economics in Honour of L.J. Savage, Amsterdam: North-Holland, 195-208.

[42] Zellner, A. (1986): "Bayesian Estimation and Prediction using Asymmetric Loss Functions", Journal of the American Statistical Association, 81, 446-451. 